\title{
Sonorants, fricatives and a tonogenetic typology
}

\author{
Gwendolyn Hyslop \\ University of Oregon
}

\section{Introduction and background}

While some phonological mechanisms underlying tonogenesis have been understood for some time (e.g. Maspero (1912), Haudricourt (1954), inter alia) ongoing research in tonogenesis suggests that the full picture is more complex than previous studies have indicated. For example, though it is generally established that voiceless initials yield high pitch register, voiced initials yield low pitch register and coda consonants condition pitch contour, the order in which segments undergo tonogenesis has barely been addressed. Additionally, tone may be conditioned by other factors such as pre-aspiration or vowel quality, amongst others.

The classical account of tonogenesis has been the model proposed by Haudricourt (1954) for Vietnamese. Diffloth (1989) reanalyzed the model to take register differences into account and Thurgood (2002) suggested updating our model of (Vietnamese) tonogenesis based on laryngeal features, arguing that intermediate stages existed. For example, voiced obstruents would condition breathy voice on their following vowel, which would in turn condition low tone.

It remains to be seen, however, how much predictive power this model has, especially given recent research on tonogenesis in Kurtöp and the other East Bodish languages (Hyslop 2009, 2010), showing that tonogenesis targets sonorants and then fricatives before developing following obstruent consonants, a finding similar to that for Athabaskan (Kingston 2005, 2007).

'Tone' refers to the primary use of fundamental frequency to make lexical/grammatical contrasts in a given language (other acoustic cues may be involved, such as voice quality, duration, etc.). This definition includes most languages which have been classified as 'pitchaccent', as well as (possibly) languages which are considered to have a 'register' distinction (cf. Thongkum 1988:328). The term 'broad tonogenesis' or simply 'tonogenesis' refers to the introduction of a tonal contrast where one did not exist previously. The term 'strict tonogenesis' is introduced here to refer to the introduction of a tonal contrast for the first time in a language, that is, the development of tone from a non-tonal parent.

\section{Methodology}

The aim of this study was to develop a typology of tonogenesis reported in the literature for a subset of languages in the literature, by examining (1) what features are likely to condition tonogenesis; and (2) whether these features are equally likely to condition strict tonogenesis. For the purposes of this study, a language was considered 'tonal' if the author stated that pitch was a salient feature used in a given word in creating a lexical or grammatical contrast. The languages considered in this study come from the Sino-Tibetan, Austroasiatic, Austronesian, IndoEuropean, Mongolic, Athabaskan, Uto-Aztecan, Algonquian, and Nilo-Saharan families.

Each tonogenetic step was coded in terms of type of trigger and laryngeal setting of trigger. 'Type' is used as an umbrella term to capture whether the trigger was a sonorant consonant, vowel, entire syllable, or the manner of the consonant, if the tonogenetic trigger was an obstruent. Sometimes authors did not state whether stops behaved differently from fricatives, for example, or sometimes used wording like 'voiced consonants'. Because of such cases, more vague categories of manner, like 'obstruent' or 'unspecified', were also allowed. Thus, possible 
trigger types were stop, fricative, sonorant, vowel, syllable, obstruent (unspecified) and all/unspecified.

Possible laryngeal settings coded in the typology were voicing, aspiration, glottalization, quality, quantity, stress, and tone. The terms 'voicing', 'aspiration' and 'glottalization' applied only to consonants. 'Quantity', 'quality' and 'tone' applied to vowels while 'stress' and 'tone' applied to syllables. For example, voiced fricatives conditioning low tone on their following vowels would be coded once for 'voicing' and once for 'fricative'.

Each tonogenetic trigger was coded once, so that instances when voiced obstruents behave one way and voiceless fricatives behave another way, 'obstruent' would be counted twice and 'voicing' would be counted twice. For example, in Athabaskan, tonogenesis is linked to glottalized sonorants, fricatives and stops. Thus the feature 'glottalized' gets coded three times, while 'sonorant', 'fricative' and 'stop' get coded once each.

Often, one tonogenetic development in a given language's history may show up as shared innovation in several daughter languages. Thus, unless there was evidence otherwise, tonogenetic events for a particular language family were coded only once. When there was evidence that tonal languages from a common source had indeed developed tone by different pathways, and that the tone was not a shared innovation (despite being a shared feature, synchronically), each tonogenetic event was coded.

\section{Results}

A total of 32 languages were coded for a total of 98 tonogenetic events. Of these, 16 were documented to be strict tonogenesis, or the development of tone in non-tonal state of the language. Due to limitations of space, details from the languages are not discussed in this abstract and we move right to the results. The results for manner are discussed below.

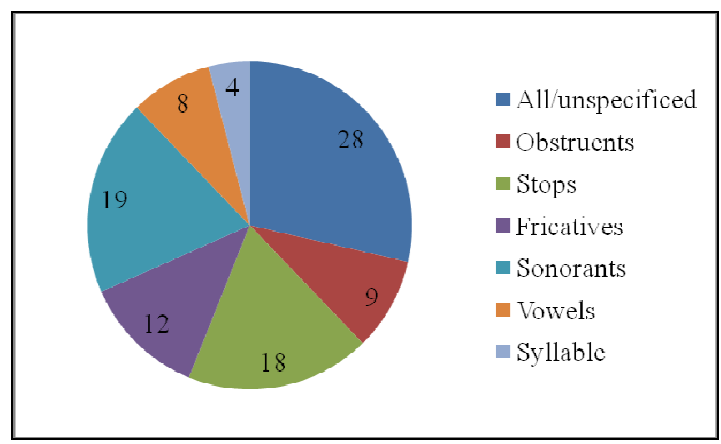

Figure 1. Conditioning factors of tonogenesis based on segment type

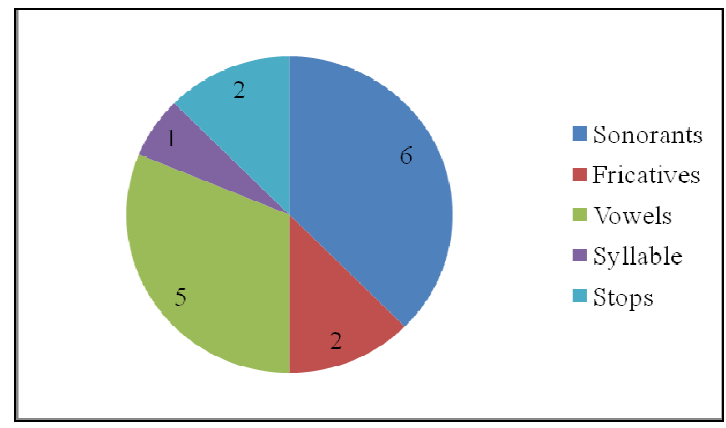

Figure 2. Conditioning factors of strict tonogenesis based on segment type 
Figure 1 illustrates the results of the typology for manner of 98 tonogenetic events. Of these 98 events, 28 , or nearly $30 \%$ involve all the consonants or instances in which the author did not specify which consonants conditioned the tonogenesis. Another 19 explicitly involved sonorants, almost the same as the number of stops, 18. Fricatives were the next largest number at 12, or roughly $12 \%$. Vowels and syllables counted for 8 and 4 instances, respectively.

The importance of sonority is salient when the results in Figure 1 are compared with the results in Figure 2. Once strict tonogenesis is taken into consideration, the stops almost completely disappear and the more vague categories like 'obstruent' or 'all' are gone altogether. The category of sonorants was the largest at 6 , followed by the category of vowels at 5 . Fricatives and stops are reported to trigger strict tonogenesis the same number of instances. Once strict tonogenesis was taken into consideration, sonorant consonants became nearly $40 \%$ of the triggers. Vowels and sonorant consonants together comprised nearly $70 \%$ of instances.

Another way to view the results is to remove the instances of strict tonogenesis from the general category, and compare strict tonogenetic events with broad tonogenetic events.

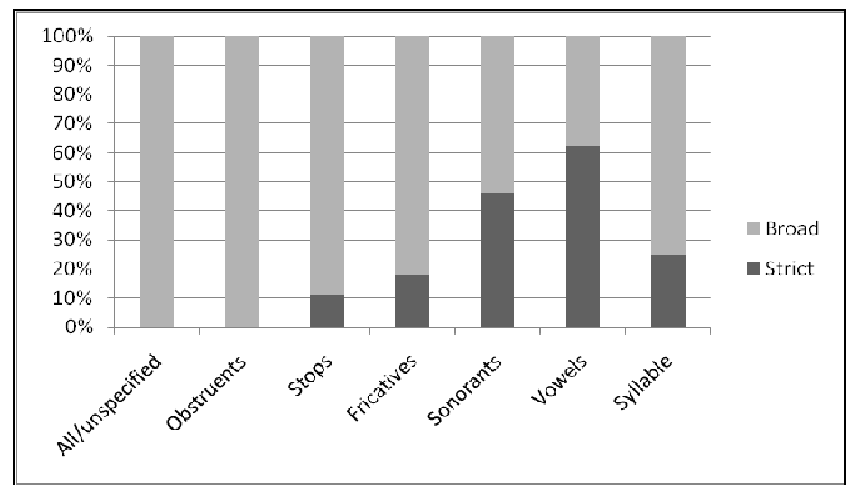

\section{Figure 3. Broad versus strict tonogenesis based on segment type}

Figure 3 illustrates percentage of strict versus broad tonogenesis, with all instances of strict tonogenesis removed from the category of broad. This is a visual representation of that fact that all consonants, or obstruents as a class of consonants, are only associated with broad tonogenesis. Stops, fricatives, sonorant consonants and vowels are associated with both strict and broad categories, but as sonority rises, the percentage of occurrences for strict tonogenesis increases and the percentage of occurrences in broad tonogenesis decreases. That is, the more sonorous a given segment is, the more likely it is to be involved in strict tonogenesis, and the less sonorous a given segment is, the less likely it is to be involved in strict tonogenesis.

\section{Conclusions}

This study developed a typology of tonogenesis as reported in the literature. Across 32 languages 98 tonogenetic events were found, of which only 16 are considered to be occurrences of strict tonogenesis. The fact that only 16 instances of strict tonogenesis were found in an examination of 32 languages, reporting a total of 98 tonogenetic events, suggests that strict tonogenesis is rarely documented. Whether this is due the lack of documentation on the part of the researcher, or the rarity of occurrence historically, remains an open question.

The finding that sonorant consonants and vowels account for the majority of occurrences of strict tonogenesis is surprising given our current models of tonogenesis, which focus on 
obstruents. Further research is warranted to examine tonogenesis in greater detail across the board, in terms of manner, or type of conditioning environment, and whether the tonogenetic event can be described as strict tonogenesis.

\section{References}

Diffloth, Gerard. 1989. Proto-Austroasiatic creaky voice. Mon-Khmer Studies 15: 139-154. Haudricourt, A. G. 1954. Comment reconstruire le chinois archäique. Word 10: 351-369.

Hyslop, Gwendolyn. 2010. Tone and tonogenesis in Bhutan and beyond: degrees of tonality? In University of British Columbia Working Papers in Linguistics, 114-124. Vancouver: University of British Columbia.

- 2009. Kurtöp Tone: A tonogenetic case study. Lingua 119, no. 6 (6): 827-845. doi:10.1016/j.lingua.2007.11.012.

Kingston, John. 2005. Athabaskan tonogenesis. In Athabaskan prosody, 137-184. Amsterdam: John Benjamins.

- 2007. Phonological pertinacity/phonetic variability presented at the University of Oregon Colloquium Series, May 25, Eugene, OR.

L-Thongkum, Theraphan. 1997. Implications of the retention of proto-voiced plosives and fricatives in the Dai Tho language of Yunnan province for a theory of tonal development and Tai language classification. In Comparative Kadai: the Thai branch, 191-219. Dallas: Summer Institute of Linguistics.

Maspero, H. 1912. Études sur la phone'tique historique de la langue Annamite: les initiales. Bulletin de l'Ecole Francaise d'Extreme Orient 12: 1-126.

Matisoff, James. 1970. Glottal dissimilation and the Lahu high-rising tone: a tonogenetic study. Journal of the American Oriental Society 90, no. 1: 13-44.

Thurgood, Graham. 1996. Language contact and the directionality of internal 'drift': the development of tones and registers in Chamic. Language 71: 1-31. 